\title{
SERO-EPIDEMIOLOGICAL STUDY OF CHRONIC RESPIRATORY DISEASE IN CHICKEN FLOCKS IN SYRIA
}

\author{
EYAD ALNAJJAR ${ }^{*}$ MOHAMMAD ALI EL-EMADI ${ }^{* *}$ and YASER ALOMAR ${ }^{* * *}$ \\ ${ }^{*}$ Student, Dept. of Animal Diseases, Vet. Med. Hama University. \\ ** Professor in Poultry Disease, Vet. Med. Hama University. \\ **** Associated Professor in Epidemiology, Vet. Med. Hama University.
}

Email: eyadvet@hotmail.com

\section{ABSTRACT}

Received at: $20 / 12 / 2014$

Accepted: 16/2/2015
It was collected 2990 blood samples from various ages of chicken of broiler, layer and breeder flocks distributed from different regions of SAR, in order to detect Mycoplasma galisepticum that used in Rapid sero- agglutination test and indirect ELISA test. The study reported sero-prevalence of positive cases using rapid sero- agglutination test $33 \%$ in broiler breeder, $1 \%$ in broiler chicken and $43 \%$ in layer chicken and overall prevalence $24 \%$. By using ELISA test, the reported sero-prevalence values $27 \%$ in breeder, $8 \%$ in broiler and $33 \%$ in layer chicken and overall-prevalence $19 \%$. The study reported markable significant differences between sero-prevalence of broiler chickens in comparing with breeders and layers flocks either using ELISA test or rapid agglutinations test $(\mathrm{p}=0.00000)$, as there were no significant differences between layers and breeders flocks using both tests. The study reported high rise- prevalence value in regions of Almobarkat and Damascus compare with other study regions and by highly markable significant differences $(\mathrm{p}=0.00000)$.

\section{دراسة وبائية مصلية للمرض التنفسي المزمن في قطعان الاجاج في سورية}

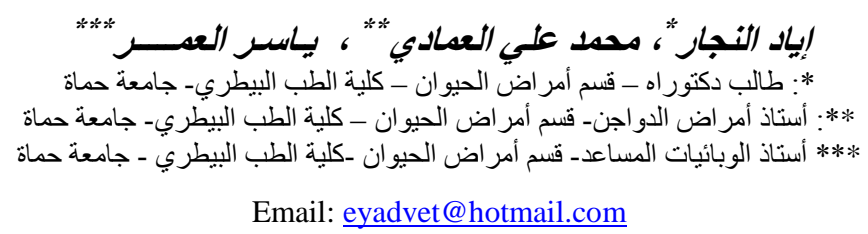

جمعت • 99 و عينة دم من طيور دجاج اللحم و البياض و أمات الفروج بأعمار مختلفة من مختلف منـاطق الجمهوريـة العربيـة السورية

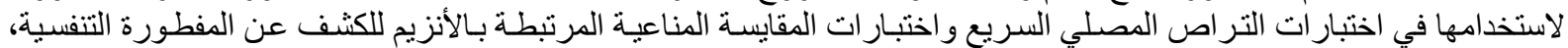

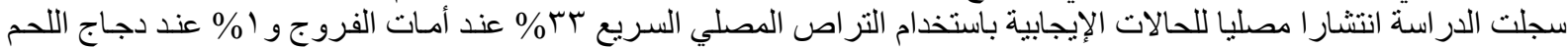

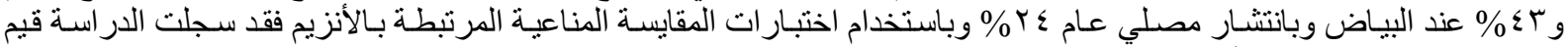

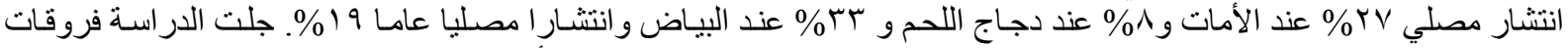

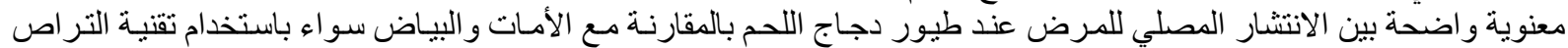

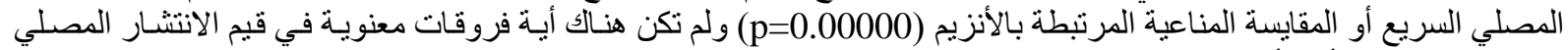

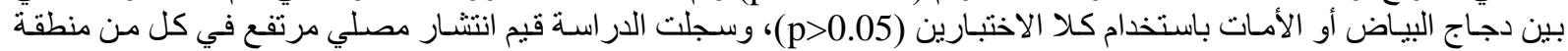

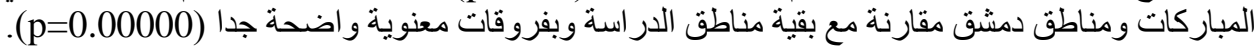

$$
\text { كلمات مفتاحية: مفطورة تتفسية_ اختبار التراص السريع - رشح مزمن }
$$




\section{INTRODUCTION}

مقدمـة

يعد مرض الرشح المزمن الذي تسببه المفطورة التنفسية (مايكوبلازما غاليسيبتكم) من أخطر الأمراض التي تسبب خسائر اقتصادية

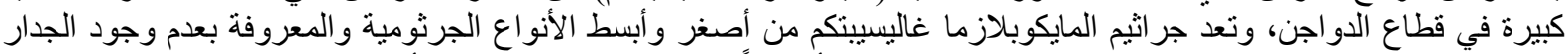

الخلوي وتتركز إمر اضيتها عند طيور الدجاج و الحبش بإحداثها أخماجاً في القناة التنفسية في جميع أنحاء العالم (Kleven, 1997).

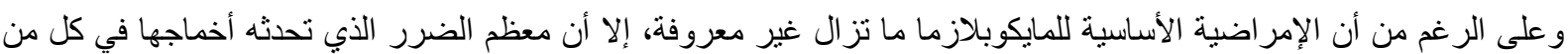

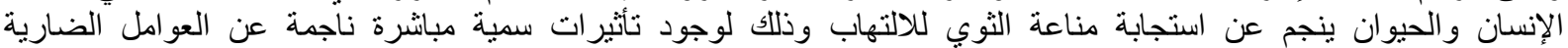

للمايكوبلازما (Razin et al., 1998).

و أثنار الباحث (Ley, 2003) إلى أن المايكوبلازما غاليسيبتكم تصيب في الحالات الطبيعية كل من طيور الدجاج والبط والحمام

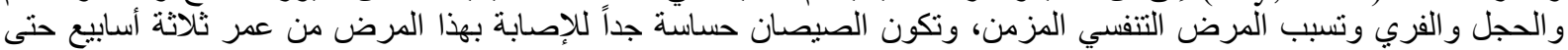

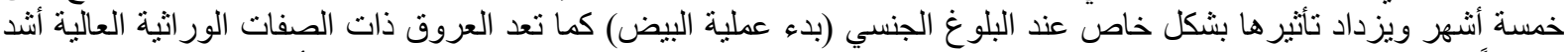

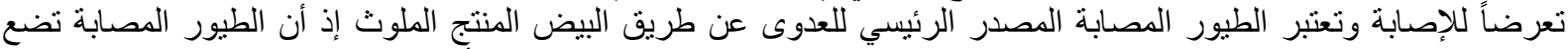

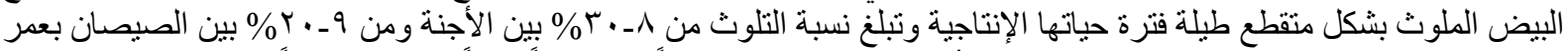

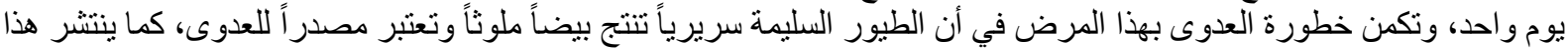

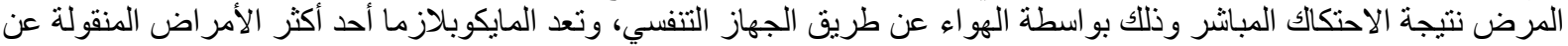

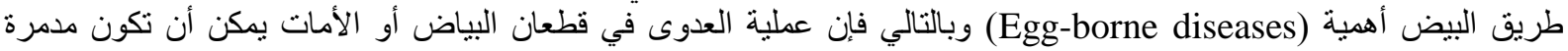
اقتصاديا وذللك بسبب الخسائر المباشرة وغير المبانرة التي تحدثها خلال دورة الإنتاج.

تمتلك جر اثيم المايكوبلازما ميزة خاصة وهي عدم قدرة الجهاز المناعي على التعرف عليها ضمن الثوي الحي، حيث أن الآلية الحيوية

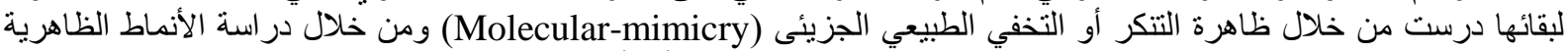
وكذللك درجة لدونتها (Phenotypes)

.(Markham et al., 1994 and Wren, 2000)

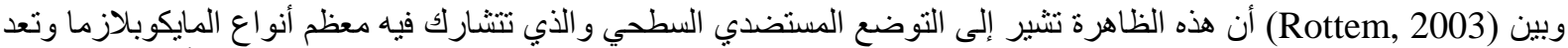

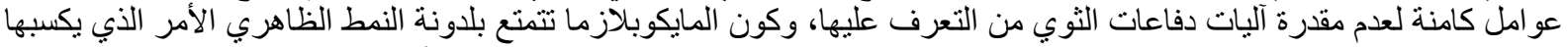

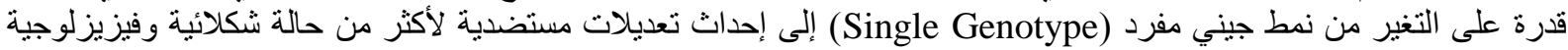

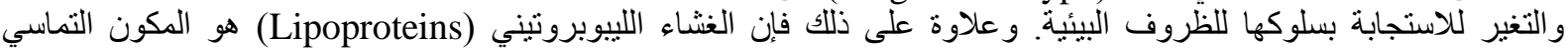

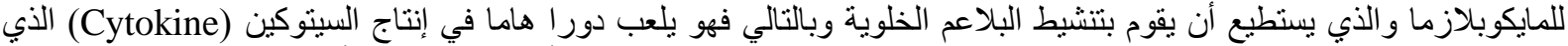

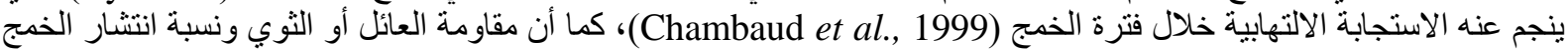
تعتمد على عوامل عدة منها الجهاز المناعي وإنتاج الخلايا الليمفاوية البائية (B-Cells) والخلايا الليمفاوية التائية (T-Cells)

.(Siegel, 1994)

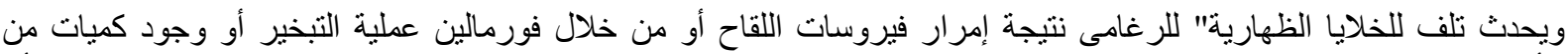

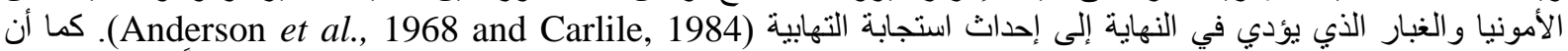

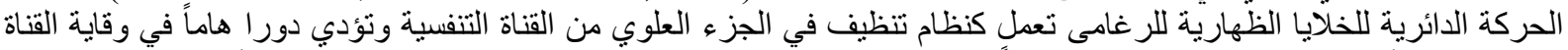

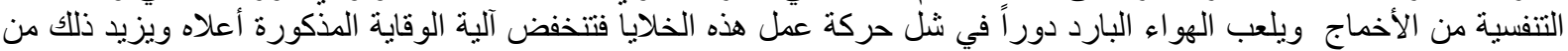

قابلية الخمج في القناة التنفسية (Bradbury, 2001).

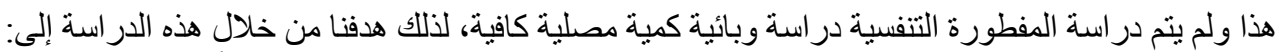

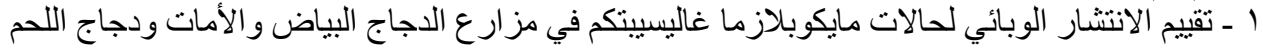

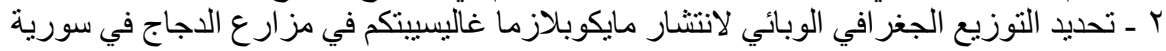

\section{MATERIALS and METHODS}

المواد وطرائق البحث

جمع العينات Samples Collection

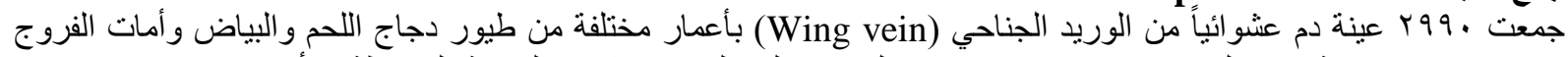

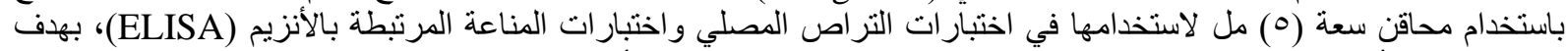

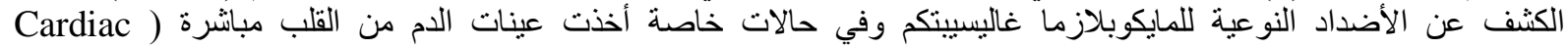
(Zencture) حسب طريقة زندر (Zander, 1978). 


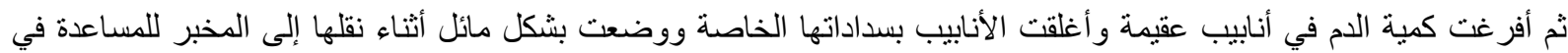

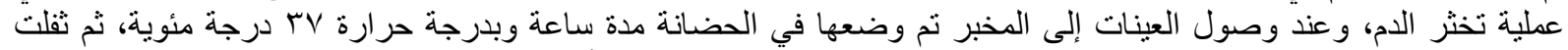

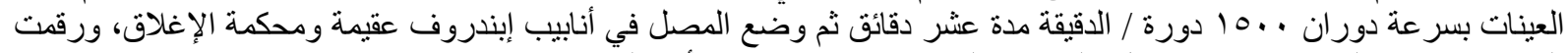

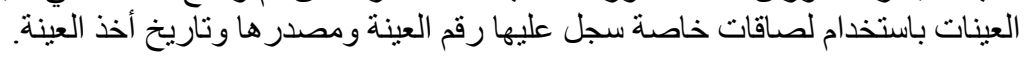

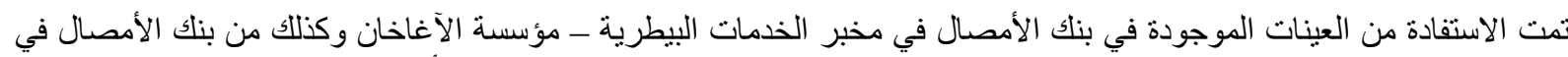
مخبر الوبائيات في كلية الطب البيطري- جامعة البعث، وييين الثكل رقم (1 ) التوزيع التكر اري لأعداد فطعان الدر اسة.

الثكل رقم ا : التوزيع التكر اري المطلق لأعداد قطعان الدراسة (فروج- بياضـ أمات)

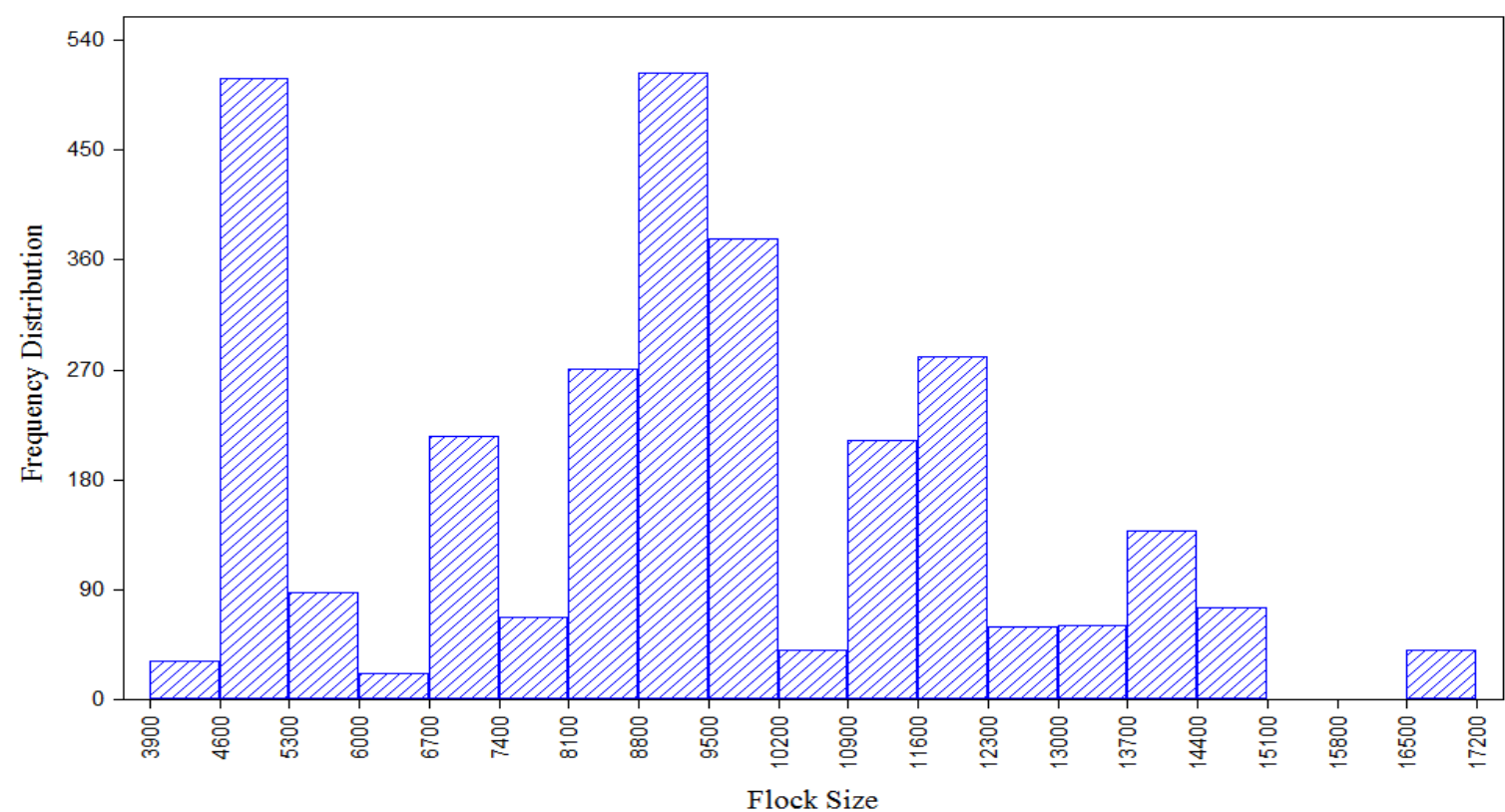

استخدمت تقنيات التراص المصلي السريع للكثف الأولي عن المايكوبلازما غاليسيبتكم ومن ثم تم اختبار نفس العينات باستخدام اختبار

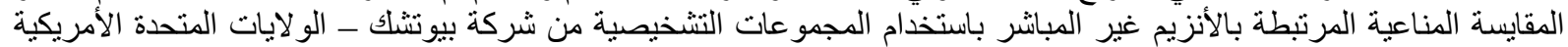

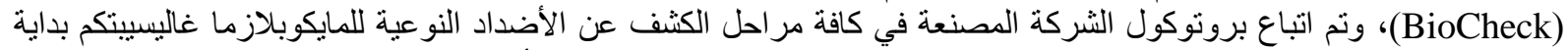

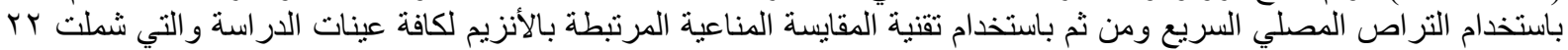
منطقة توز عت على الت آ قطيعا خلال فترة الدراسة موز على على مختلف مناطق القطر العربي السوري.

وقدر الانتشار الدصلي حسب كل من الباحثين (McNeil, 1998) and (Martin et al., 1987) و (Alomar, 2000). وتمت مقارنة نتائج نسب الانتشار المصلي بين أنماط التربية في الدراسة وبين منطقة وأخرى باستخدام اختبار بيرسون مربع كاي (Pearsons Chi Square)

\section{RESULTS}

النتائـج

يبين الجدول رقم ( ) نتائج الحالات الإيجابية للمايكوبلازما غاليسييتكم باستخدام اختبار التراص السريع المصلي حسب نوع التربية ، التباتية ،

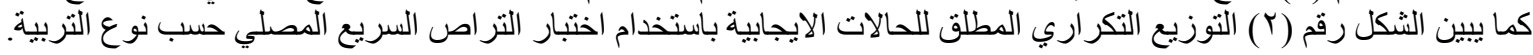


Assiut Vet. Med. J. Vol. 61 No. 144 January 2015

الجدول رقم ا : نتائج الحالات الإيجابية للمايكو بلازما غاليسيبتكم باستخدام اختبار التر اص السريع المصلي حسب نوع التربية

\begin{tabular}{|c|c|c|c|c|}
\hline نسبة الانتثار \% & أعداد الحالات السلبية & أعداد الحالات الإيجابية & العينات & نوع التربية \\
\hline Tr & 91. & $\varepsilon \varepsilon$. & iro. & أمات \\
\hline 1 & $110 \varepsilon$ & Irs & ITVA & فروج \\
\hline$\varepsilon r$ & $r \cdot \Lambda$ & $10 \varepsilon$ & Trt & 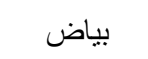 \\
\hline$r \varepsilon$ & TrVT & Vis & rqq. & المجموع \\
\hline
\end{tabular}

الثكل رقم ץ : التوزيع التكر اري المطلق للحالات الإيجابية باستخدام اختبار التراص السريع المصلي حسب نوع التربية:

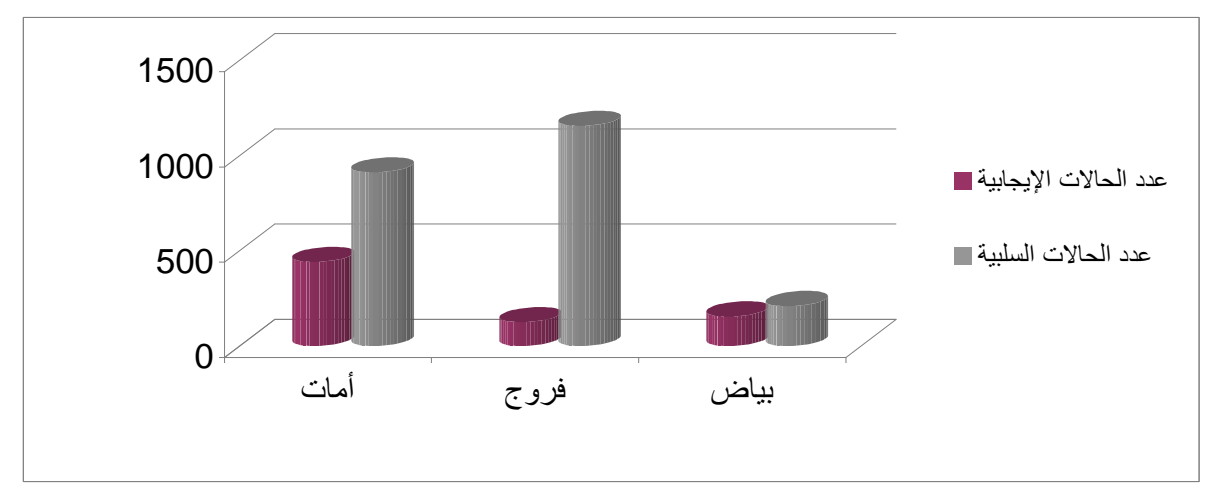

الجدول رقم ب: نتائج الحالات الإيجابية للمايكوبلازمـا غاليسيبتكم باستخدام اختبار المقايسة المناعية المرتبطة بـالأنزيم حسب نوع

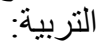

\begin{tabular}{|c|c|c|c|c|}
\hline الانتشار \% \% & عدد الحالات & عدد الحالات & عدد العينات & نوع التربية \\
\hline rV & 99. & . & 1 & أمات \\
\hline$\wedge$ & 1119 & 91 & I TVA & فروج \\
\hline rr & $r \leq 1$ & $|r|$ & rTr & بياض \\
\hline 19 & $r \leqslant r$. & ovq & rq9. & المجموع \\
\hline
\end{tabular}

الثكل رقم بّ: التوزيع التكر اري المطلق للحالات الإيجابية باستخدام اختبار المقايسة المناعية المرتبطة بالأنزيم:

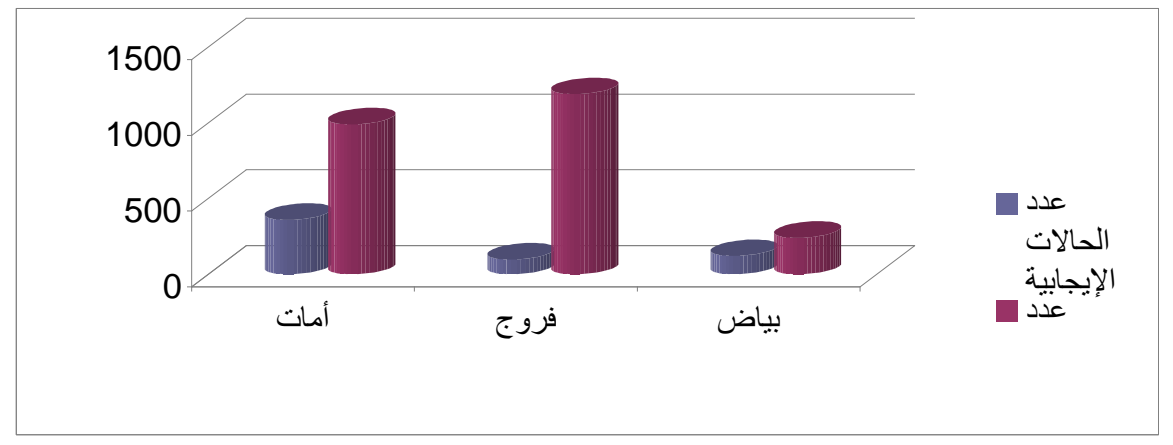


Assiut Vet. Med. J. Vol. 61 No. 144 January 2015

جدول رقم ץ: التوزيع النسبي لحدوث الحالات الإيجابية للمايكوبلازما غاليسيتكم باستخدام تقنية التر اص السريع المصلي لكافة أنماط التربية وحسب المنطقة الجغر افية الإني

\begin{tabular}{|c|c|c|c|c|}
\hline الانتشار \% & عدد الحالات السلبية & عدد الحالات & العينات & المنطقة \\
\hline 11 & $V \leqslant V$ & 177 & $91 \pi$ & سلمية \\
\hline 9 & orv & 00 & 094 & حلب \\
\hline$r$ & TYS & 07 & $r \wedge$. & حماة \\
\hline . & $r q$ & . & $r q$ & الفانات \\
\hline 71 & $r$. & MI & 01 & المباركات \\
\hline rT & $T \cdot V$ & 91 & $r .0$ & حمص \\
\hline 1 & $\cdot$ & 17 & 17 & تل الدرة \\
\hline 09 & Or & $V \varepsilon$ & $1 \times 7$ & دمشق \\
\hline$\sum r$ & TYY & 19 & YII & ادلب \\
\hline$\cdot$ & TY & $\cdot$ & TY & تل كلخ \\
\hline$\cdot$ & 9 & $\cdot$ & 9 & حماة_قمحانة \\
\hline$\cdot$ & 19 & $\cdot$ & 19 & حماة_كفراع \\
\hline 1 & . & 19 & 19 & حماة_شمال كفر اع \\
\hline 0 & 11 & 1 & 19 & حماة_الغاب \\
\hline$\cdot$ & r) & $\cdot$ & rI & حماة_السعن \\
\hline$\varepsilon r$ & rq & rq & 71 & الرقة \\
\hline$\cdot$ & $r \cdot$ & $\cdot$ & $r \cdot$ & حمص_القصير \\
\hline 1 & $\cdot$ & $\varepsilon$ & $\varepsilon$ & طرطوس-صافيتا \\
\hline$r T$ & $7 V$ & $T r$ & 9. & اللاذقية-جبلة \\
\hline$r$ & 79 & $T$ & $V \cdot$ & طرطوس \\
\hline Tr & TV & $1 T$ & $\varepsilon \cdot$ & دير الزور \\
\hline 00 & 9 & 11 & $r$. & دمشق-صيدنايا \\
\hline$T \varepsilon$ & TYYA & VYY & rq9. & الإجمالي العام \\
\hline
\end{tabular}

جدول رقم ؛ : التوزيع النسبي لحدوث الحالات الإيجابية للمايكوبلازما غاليسيبتكم باستخدام تقنية الاليزا الغير مباشرة لكافة أنماط التربية حسب المنطقة الجغر افية الحية

\begin{tabular}{|c|c|c|c|c|}
\hline الانتشار \% & عدد الحالات السلبية & عدد الحالات الإيجابية & عدد العينات & المنطقة \\
\hline 10 & $V \wedge$. & 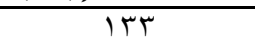 & $91 \%$ & سلمية \\
\hline 7 & $00\}$ & rᄉ & 094 & حلب \\
\hline$\pi$ & $r \leqslant 0$ & ro & rA. & حماة \\
\hline$\cdot$ & $r 9$ & $\cdot$ & rq & الفانات \\
\hline 00 & Tr & TA & 01 & المباركات \\
\hline TY & TrV & 71 & $r .0$ & حمص \\
\hline 1 & $\cdot$ & 17 & 17 & تل الدرة \\
\hline Or & 71 & 70 & $1 \% 4$ & دمشق \\
\hline$r 9$ & $\pi$ & NI & YाI & ادلب \\
\hline$\cdot$ & TY & $\cdot$ & TY & تل كلخ \\
\hline$\cdot$ & 9 & . & 9 & حماة_قمحانة \\
\hline$\cdot$ & 19 & $\cdot$ & 19 & حماة_كفراع \\
\hline$\cdot$ & $\cdot$ & 19 & 19 & حماة_شمال كفر اع \\
\hline$\cdot$ & 19 & $\cdot$ & 19 & حماة_الغاب \\
\hline . & YI & $\cdot$ & YI & حماة_السعن \\
\hline TA & $\sum 9$ & 19 & 71 & الرقة \\
\hline$\cdot$ & $r$. & $\cdot$ & $r$. & حمص_القصير \\
\hline 1 & $\cdot$ & $\varepsilon$. & $\varepsilon$. & طرطوس-صافيتا \\
\hline TY & $V \cdot$ & $r \cdot$ & 9. & اللاذقية-جبلة \\
\hline . & $V$. & . & $V \cdot$ & طرطوس \\
\hline Tr & 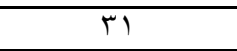 & 9 & $\varepsilon$ & دير الزور \\
\hline 00 & 9 & 11 & $r \cdot$ & دمشق-صيدنايا \\
\hline 19 & $r \leq \cdot \Lambda$ & ONY & r99. & الإجمالي العام \\
\hline
\end{tabular}


الثكل رقم ؛ : التوزيع النسبي لانتشار الحالات الإيجابية للمفطورة التنفسية حسب المنطقة الجغرافية في الدراسة وباستخدام تقنية الإليز أغير المبانشرة

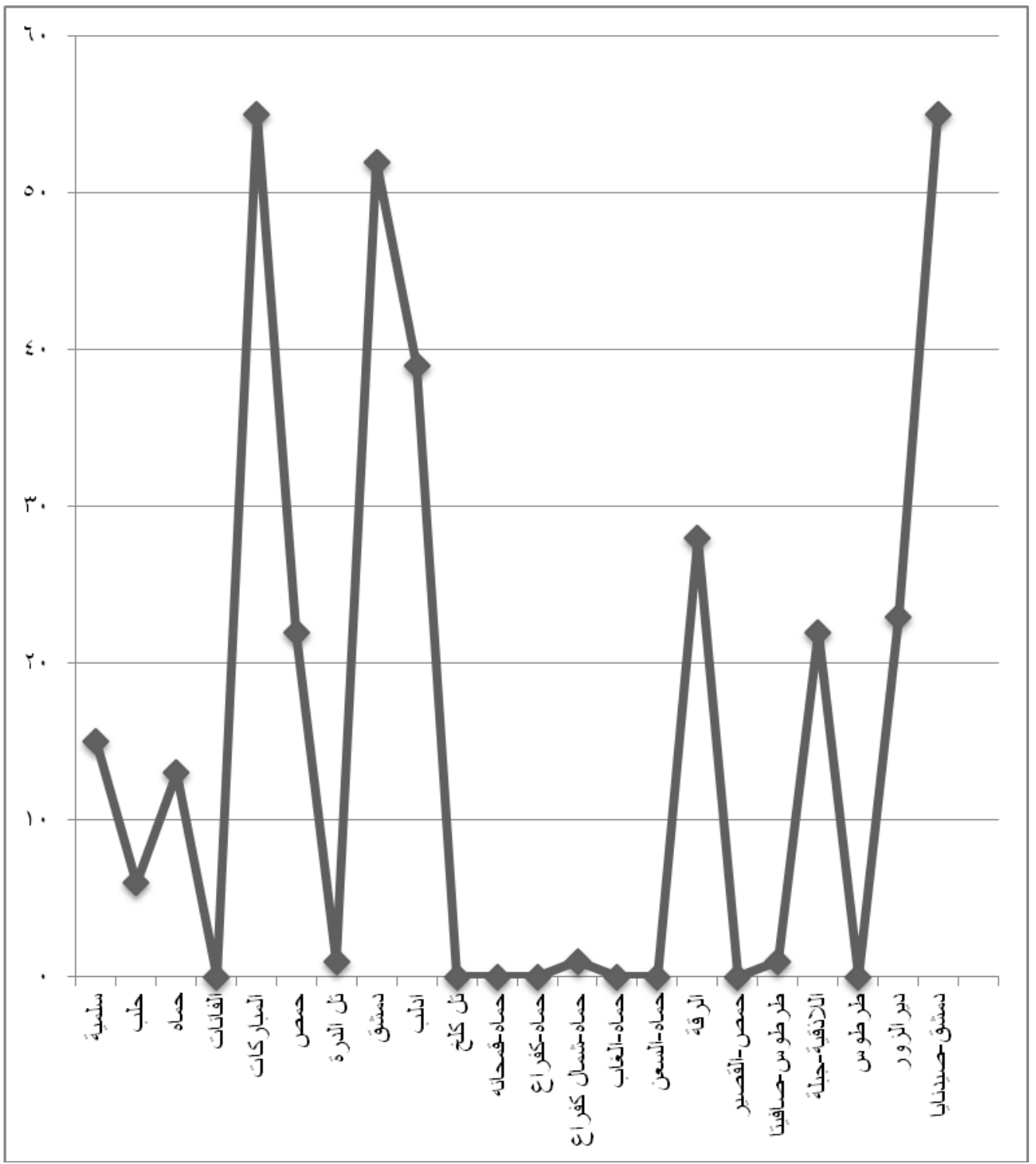

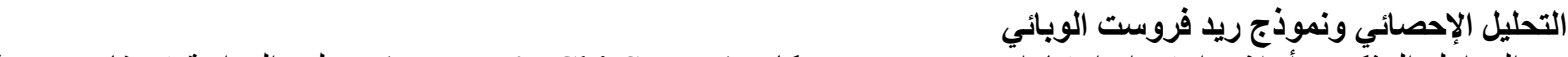

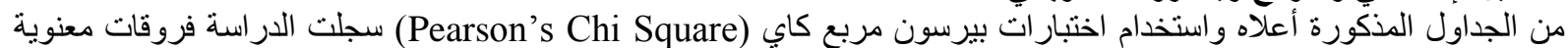

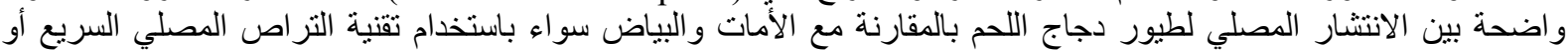

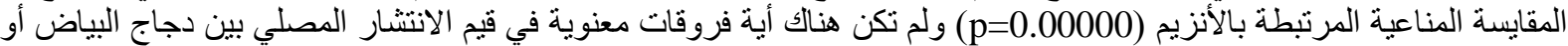
الأمات باستخدام كلا الاختبارين (p>0.05).

وسجلت الدراسة قيم انتشار مصلي مرتفع في كل من منطقة المباركات ومناطق دمشق مقارنة مع بقية مناطق الدراسة وبفروقات معنوية واضحة جدا (p=0.0000).

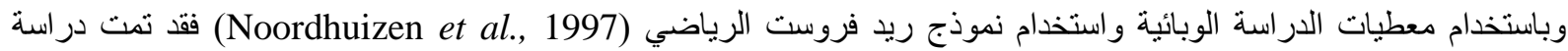

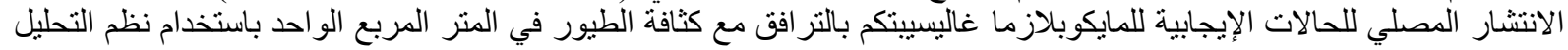

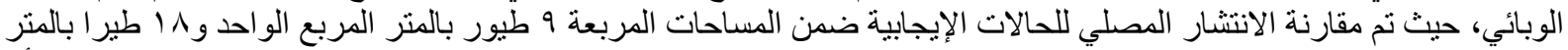

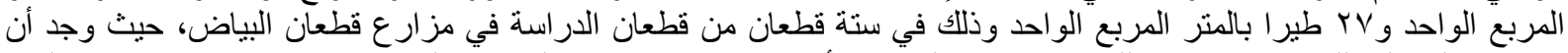

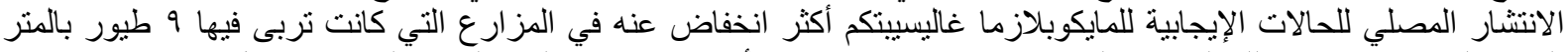

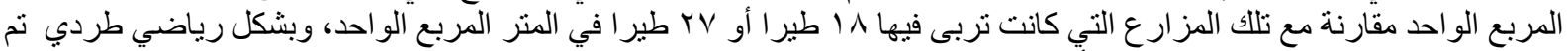

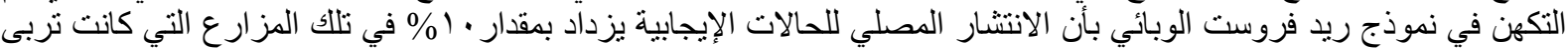

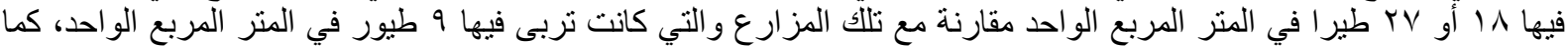

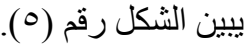


الثكل رقم ه: علاقة كثافة التربية مع الإصابة بالمايكوبلازما غاليسيتكم

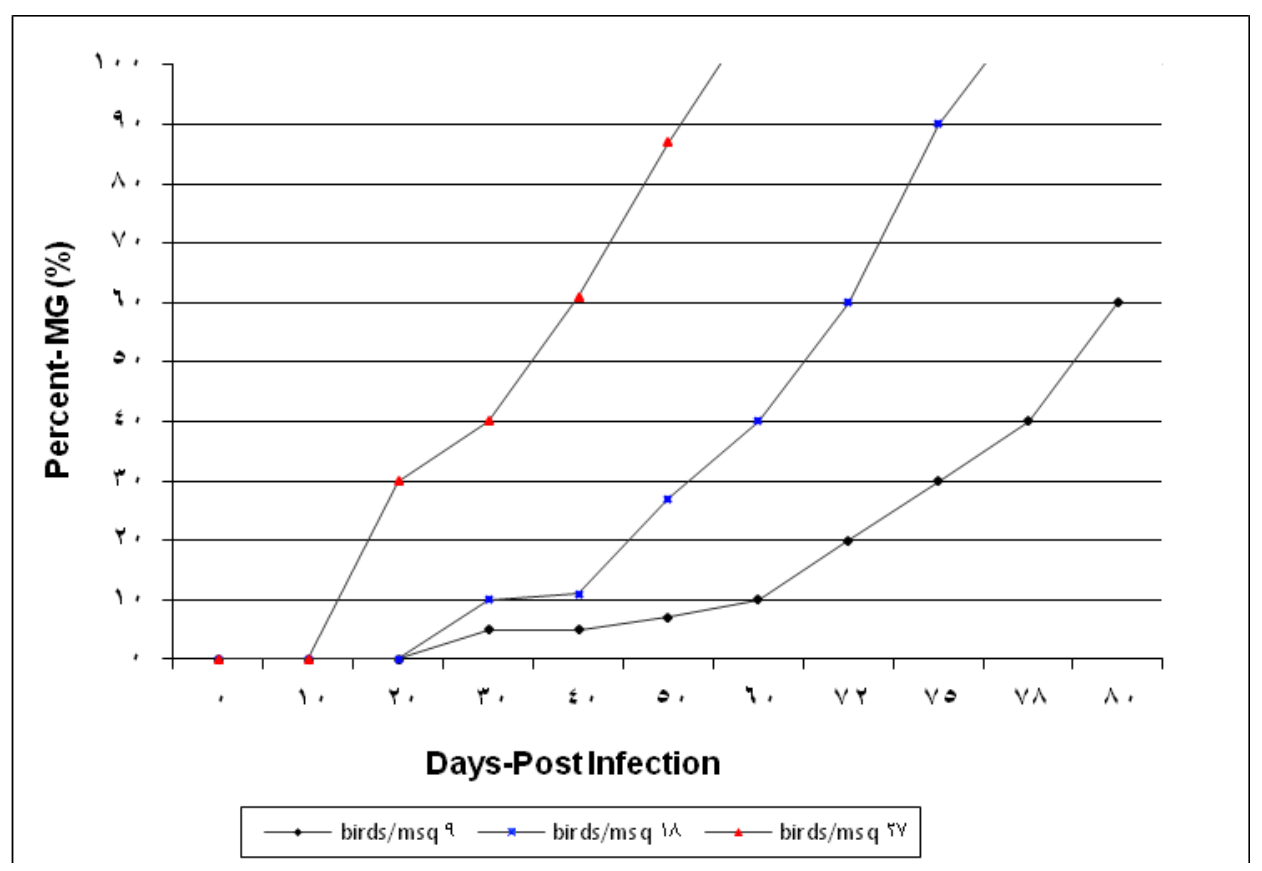

\section{DISCUSSION المناقشــة}

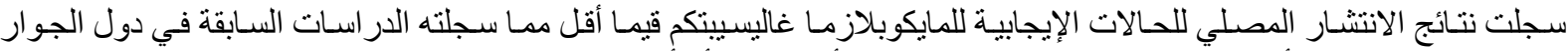

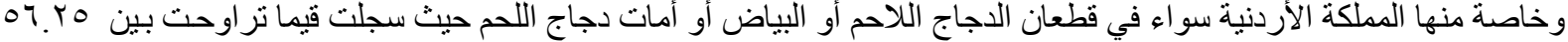

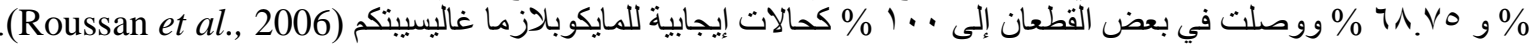

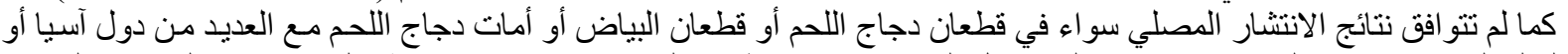

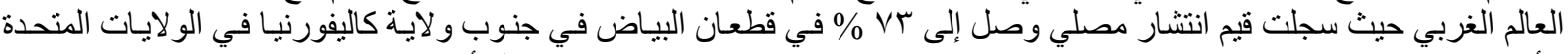

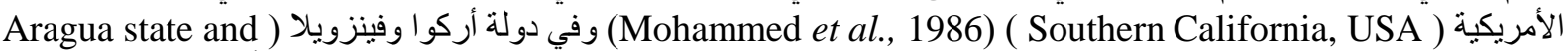

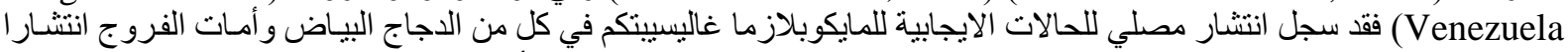

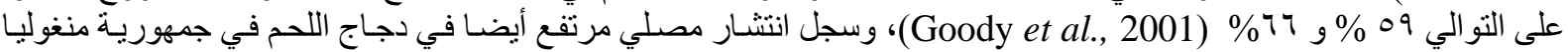

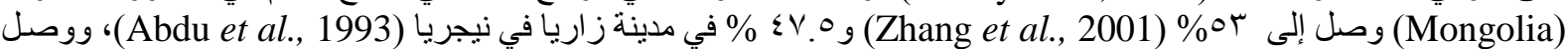

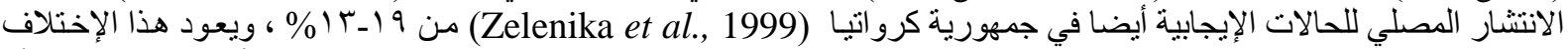

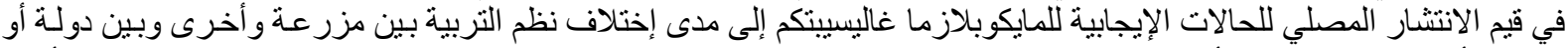

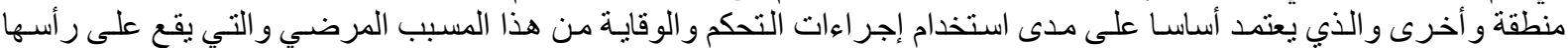
استخدام التحصين وفترة التحصين و انتشار الوباء في كل منطقة وأخرى.

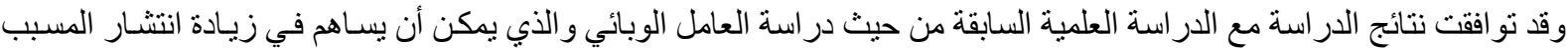

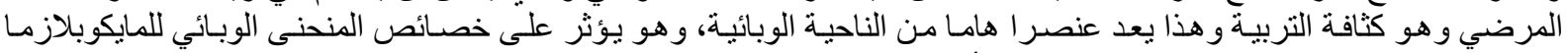

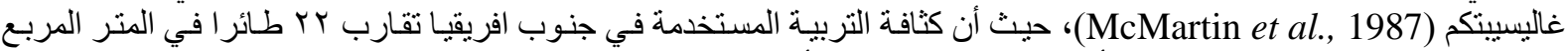

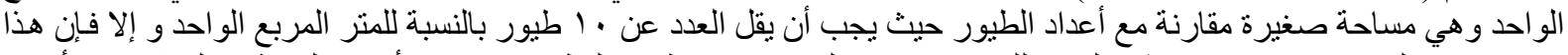

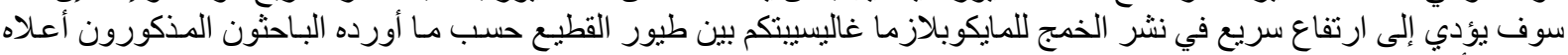

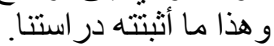

نستتنج مما سبق أن المايكوبلازما غاليسيبنكم سجلت انتشار مصليا مرتفعا نو عا ما في كل من الدجاج البياض وأمات دجاج اللحم وهذا

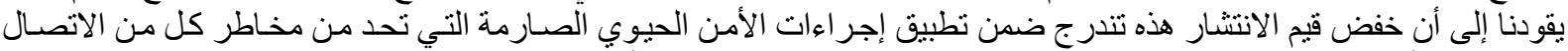

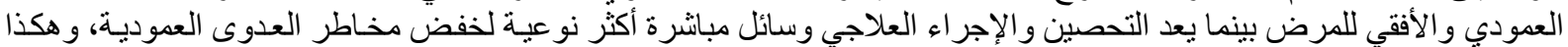

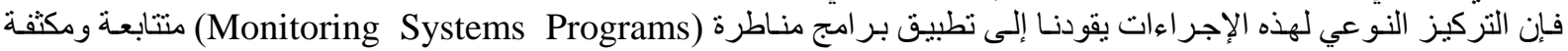

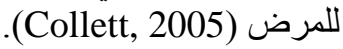




\section{REFERENCES}

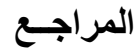

Abdu, P.A.; Bishu, G.; Adysiyun, A.A. and Adegboye, D.S. (1993): Survey for Mycoplasma gallisepticum and Mycoplasma Synoviae antibodies in Chicken in Saria, Nigeria. Journal of Animal Production Research, 3: 63-69.

Alexander, D.J. (1997): Newcastle Disease and Other Avian Paramyxoviridae Infections. In Diseases of Poultry, pp. 541-569. Edited by B. W. Calnek, Ames, Iowa State University Press.

Alomar, Y. (2000): Epidemiological methods to estimate the impact of production diseases in dairy herds. $\mathrm{Ph}$. Thesis, Reading University, UK.

Analytical software, (2002): Statistix, version 4.0. Windows Version. United State of America.

Bradbury, J.M. (2001): Avian Mycoplasmas. In: Poultry Diseases, Fifth Edition, Jordan F., Pattison M., Alexander D. \& Faragher T., eds. W.B Saunders, London, UK, 178-193.

Carlile, E. S. (1984): Amonia in Poultry Science Journal, 40: 99-113.

Chambaud, I.; Wroblewski, H. and Blanchard, A. (1999): Interactions between Mycoplasma Lipoproteins and the Host Immune System. Trends Microbiol 7: 493-499.

Collett, S.R. (2005): Monitoring Broiler Breeder Flocks for Mycoplasma Gallisepticum after Vaccination with tS-11. MSc Thesis. Department of Production Animal Studies, Faculty of Veterinary Science, University of Pretoria.

Godoy, A.; Andre, L.F.; Colmenares, O.; Bermudez, V.; Herrera, A. and Munoz, N. (2001): Prevalence of Mycoplasma gllisepticum in egg-laying hens. Veterinary Tropical Journal, 26: 25-33.

Kleven, S.H. (1997): Mycoplasma synoviae infection. In: Calneck BW, Barnes HJ, Beard CW, MacDougald LR and Saif YM. (eds) Diseases of Poultry. 9th edition. Iowa State University Press, Ames, pp 220-228.

Ley, D.H. (2003): Mycoplasma Gallisepticum Infection. In: Diseases of Poultry, Eleventh Edition, Saif Y.M., Barnes H.J., Glisson J.R., Fadly A.M., McDougald L.R. \& . Swayne D.E., eds. Iowa State University Press, Iowa, USA, 722-744.

Markham, P.F.; Glew, M.D.; Sykes, J.E.; Bowden, T.R.; Pollocks, T.D.; Browning, G.F.; Withear, K.G. and Walker, I.D. (1994): The Organization of the Multigene Family which Encodes the Major Cell Surface Protein pMGA, of Mycoplasma gallisepticum. FEBS Lett 352:347-352.

Martin, W.S. Meek, H.A. and Wille, P.W. (1987): Veterinary Epidemiology .first Edition. Iowa state University, Press, Ames, Iowa 50014, P343.

McMartin, D.A.; Khan, M.I.; Farver, T.B. and Christie, G. (1987): Delineation of the Lateral Spread of Mycoplasma Gallisepticum Infection in Chicken. Avian Diseases, 31: 814-819.

McNeil, D. (1998): Epidemiological research methods. Johon Wiley \& Sons Ltd. UK.

Mohammad, H.O.; Carpenter, T.E.; Yamamoto, R. and McMartin, D.A. (1986): Prevalence of Mycoplasma Gallisepticum and M. Synoviae in commercial layers in Southern and Central California. Avian Diseases, 30: 519-526.

Noodhuizen, J.P.T.M.; Frankena, K.; Van der Hoofd, C.M. and Graat, E.A.M. (1997): Application of Quantitative Methods in Veterinary Epidemiolopgy. Wageningen Pres, USA, P-247-269

Razin, S.; Yogev, D. and Naot, Y. (1998): Molecular Biology and Pathogenicity of Mycoplasmas. Microbiol Mol Biol. Rev., 62:1094-1156.

Rottem, S. (2003): Interaction of Mycoplasmas with Host Cells. Physiol. Rev. 83: 417-423.

Roussan, D.A.; Abu-Basha, E.A. and Haddad, R. (2006): Control of Mycoplasma Gallisepticum Infection in Commercial Broiler Breeder Chicken Flocks Using Tilmicosin (Provitil Powder ®) Oral Formulation. International Journal of Poultry Science, No. 5, Vol. 10.

Wren, B.W. (2000): Microbial Genome Analysis: Insights into Virulence Host Adaptation and Evolution. Nat. Rev. Genet, 1:30-39.

Zelenika, T.A.; Savic, V. and Balenovic, M. (1999): Mycoplasmosis in heavey hybrid hens in Croatia from 1993 to 1998 Stocarstvo, 5: 411-418.

Zhang, J.H.; Bi, D.R.; Wang, M.H.; Han, B. and Gao, A.X. (2001): Prevalence and pathogenicity of Mycoplasma gallisepticum in broilers in Inner Mongolia. Chin. J. Vet. Sci. Tec., 31: 12-13. 